\title{
Sniffing on Microbes: Diverse Roles of Microbial Volatile Organic Compounds in Plant Health
}

\author{
Vasileios Bitas, ${ }^{1}$ Hye-Seon Kim, ${ }^{2}$ Joan W. Bennett, ${ }^{3}$ and Seogchan Kang ${ }^{1}$ \\ ${ }^{1}$ Department of Plant Pathology \& Environmental Microbiology, The Pennsylvania State University, University Park 16802 , \\ U.S.A.; ${ }^{2}$ Department of Biological Sciences, University of Delaware, Newark 19711, U.S.A.; ${ }^{3}$ Department of Plant Biology \\ and Pathology, Rutgers University, New Brunswick, NJ 08901, U.S.A.
}

Submitted 18 October 2012. Accepted 3 April 2013.

Secreted proteins and metabolites play diverse and critical roles in organismal and organism-environment interactions. Volatile organic compounds (VOC) can travel far from the point of production through the atmosphere, porous soils, and liquid, making them ideal info-chemicals for mediating both short- and long-distance intercellular and organismal interactions. Critical ecological roles for animal- and plant-derived VOC in directing animal behaviors and for VOC as a language for plant-to-plant communication and regulators of various physiological processes have been well documented. Similarly, microbial VOC appear to be involved in antagonism, mutualism, intra- and interspecies regulation of cellular and developmental processes, and modification of their surrounding environments. However, the available knowledge of how microbial VOC affect other organisms is very limited. Evidence supporting diverse roles of microbial VOC with the focus on their impact on plant health is reviewed here. Given the vast diversity of microbes in nature and the critical importance of microbial communities associated with plants for their ecology and fitness, systematic exploration of microbial VOC and characterization of their biological functions and ecological roles will likely uncover novel mechanisms for controlling diverse biological processes critical to plant health and will also offer tangible practical benefits in addressing agricultural and environmental problems.

Every organism employs a network of signaling pathways to sense the environment and other organisms and to launch one or more specific molecular, cellular, or developmental changes. This signaling mechanism ensures cellular homeostasis, directs orderly growth and development, and controls behavior. Because sensing of the environment and other organism occurs often through the recognition of specific molecules, a vast array of secreted proteins and metabolites play key roles in these mechanisms. In turn, many organisms also have evolved the ability to exploit these mechanisms in other organisms to benefit themselves or coordinate symbiosis (Bednarek et al. 2010;

Corresponding author: S. Kang; E-mail: sxk55@psu.edu; Telephone: +1.814.863.3846; Fax: +1.814.863.7217.

* The $\boldsymbol{e}$-Xtra logo stands for "electronic extra" and indicates that Figure 1 appears in color online.

(c) 2013 The American Phytopathological Society
Bonfante and Anca 2009). The following examples illustrate the critical significance of secreted molecules for the health and fitness of plants: i) manipulation of physical and chemical properties of soil (e.g., organic acids to facilitate phosphorus acquisition and to chelate toxic heavy metals) and ii) control of interspecies interactions (e.g., allelopathy; volatile compounds to attract pollinators, seed dispersers, and parasitoids of herbivorous insects; antimicrobial compounds and proteins for defense; flavonoids to initiate the formation of symbiosomes by rhizobia; and strigolactones for mycorrhizal symbiosis).

Plant-associated microbes also secrete various molecules that affect plant health both directly and indirectly (Bednarek et al. 2010; Bonfante and Anca 2009): i) altering physical and chemical properties of their immediate surroundings to increase nutrient availability for themselves and associated plants (e.g., siderophores for iron acquisition and enzymes and metabolites to facilitate phosphorus acquisition), ii) antagonizing pathogenic organisms (e.g., antibiotics and antimicrobial proteins), and iii) priming host cells for subsequent colonization (e.g., modulation of external $\mathrm{pH}$ to facilitate pathogenesis and molecules that coordinate symbiosis or quorum sensing). Pathogenic microbes secrete assorted virulence factors (or effectors) into plant-pathogen interspaces and the cytoplasm of host cells via specialized secretion systems, in order to attenuate host defense responses and support pathogen proliferation (Martin and Kamoun 2012). Plants have evolved to recognize certain pathogen-derived molecules as signals in the species- or isolate-specific (e.g., avirulence factors) and non-species-specific (e.g., fungal cell wall components and bacterial flagella and lipopolysaccharides) manners in order to initiate rapid and strong defense responses (Thomma et al. 2011). Collectively, molecules secreted by plants and microbes affect the structure and emergent properties of plant-associated microbial communities as well as the health of plants and soils (Bednarek et al. 2010; Berendsen et al. 2012; Lundberg et al. 2012).

Organisms ranging from microbes to animals to plants secrete volatile organic compounds (VOC) that affect their environments and each other (Fig. 1) (Baldwin 2010; Effmert et al. 2012; Herrmann 2010; Kramer and Abraham 2012; Morath et al. 2012; Schulz and Dickschat 2007). Biogenic VOC exhibit certain common chemical and physical properties: they i) belong to chemical classes such as alcohols, thiols, aldehydes, esters, terpenoids, and fatty acid derivatives; ii) are usually lipophilic; and iii) have low molecular weight $(<300 \mathrm{Da})$ and high vapor pressure $\left(0.01 \mathrm{kPa}\right.$ or higher at $\left.20^{\circ} \mathrm{C}\right)$, such that they evaporate easily at normal temperatures and pressures (Schulz and Dickschat 2007). VOC are often less diverse than 
nonvolatile compounds secreted by individual organisms, helping in their analysis. Analysis of VOC typically relies on gas chromatography mass spectrometry (GC-MS), which integrates the separation capability of GC with MS that can identify and quantify individual compounds. Rapid advances in GC-MS have enabled comprehensive profiling and identification of VOC (Reaves and Rabinowitz 2011; Sardans et al. 2011; Zhang and Li 2010).

Due to their ability to move through air spaces as well as liquids (Effmert et al. 2012), VOC can serve as ideal signaling molecules (semio- or info-chemicals) for mediating both shortand long-distance intercellular and organismal interactions. VOC from animals and their associated microbes guide biting insects to their prey (Baldwin 2010; Ezenwa et al. 2012; Herrmann 2010; Verhulst et al. 2011). Plants are perhaps the most prolific producers of VOC (Baldwin 2010; ClavijoMcCormick et al. 2012; Herrmann 2010). It is estimated that, collectively, plants produce close to 30,000 different VOC using as much as $20 \%$ of their fixed $\mathrm{CO}_{2}$ (Baldwin 2010). Not surprisingly, plant VOC seem to perform diverse and critical functions, one of which is mediating communications with other organisms (Baldwin 2010; Clavijo-McCormick et al. 2012; Wenke et al. 2010). Attraction of pollinators and seed dispersers via the release of VOC by flowers and fruits, respectively, ensures reproductive success. Volatiles released from tissues damaged by herbivory attract predators and parasitoids of herbivores (Baldwin 2010; Clavijo-McCormick et al. 2012). A recent review outlines how mixtures of herbivore-induced VOC encode specific messages, such as the nature and developmental status of the herbivore, to predators and parasitoids (Clavijo-McCormick et al. 2012). Volatile hormones and hormone derivatives, such as ethylene, methyl jasmonate, and methyl salicylate (Fig. 2), control plant defense responses (Baldwin 2010; Robert-Seilaniantz et al. 2011). These signals also participate in priming neighboring tissues and plants for stronger and more rapid defense responses in case they are attacked (Yi et al. 2010). Some VOC contribute to defense via their antimicrobial activities (Baldwin 2010). For example, tomato leaves treated with chitosan oligosaccharide, a degradation product of the fungal cell wall, induced the production of VOC that inhibit fungal pathogen growth (Zhang and Chen 2009). Spices and herbs are prized for their prolific production of essential oils, which effectively protect against diverse pathogenic microbes (Cheng et al. 2005; Kordali et al. 2005; Soylu et al. 2007). Some plant VOC also participate in moderating abiotic stresses, such as extreme temperatures, high light intensity, drought, salinity, mechanical damage, and pollutants (Vickers et al. 2009). More comprehensive information about plant VOC and their functions can be found in the following reviews: Baldwin (2010), Clavijo-McCormick and associates

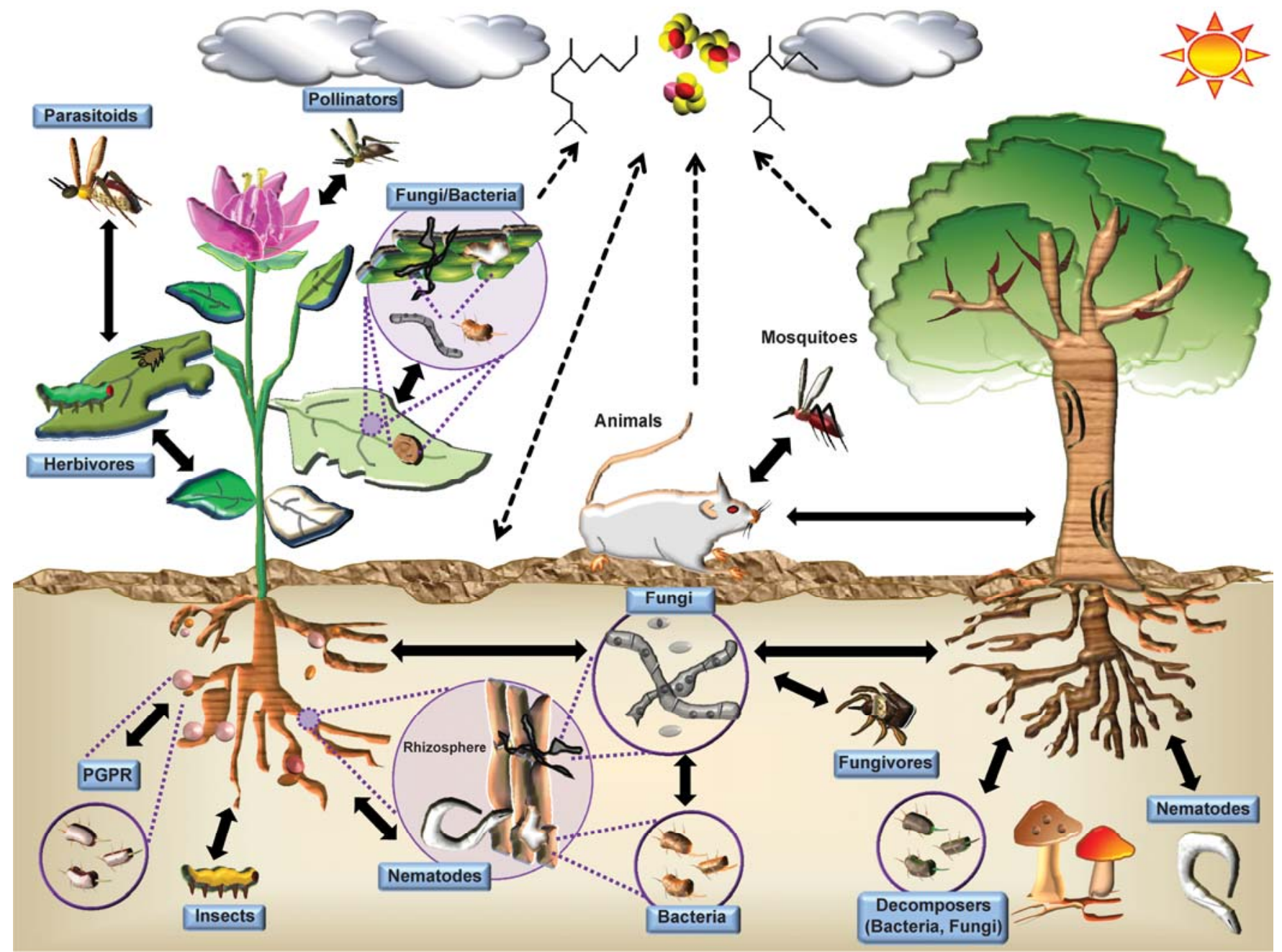

Fig. 1. Known and hypothesized roles of volatile organic compounds (VOC) in mediating organismal interactions within and across kingdoms. The doubleheaded arrows denote VOC-mediated organismal interactions. Anthropogenic and biogenic VOC enter the surrounding atmosphere, potentially affecting the environmental quality and ecosystem health. Soils function as both sources and sinks of VOC. Certain VOC produced by plant growth-promoting rhizobacteria (PGPR), such as 2,3-butanediol, induce plant growth and stress resistance. 
(2012), Heil and Karban (2010), Herrmann (2010), Kant and associates (2009), and Yi and associates (2010).

Similarly, there is increasing evidence that microbial VOC play cognate roles in mediating antagonism, mutualism, intraand interspecies regulation of cellular and developmental processes, and modification of their surrounding environments. However, compared with plant VOC, our knowledge about the biological and ecological roles of microbial VOC is limited. In this review, we highlight the nature and known or proposed functions of bacterial and fungal VOC with a focus on those that affect plant health directly or indirectly. Due to the space limitation, we are unable to discuss all relevant studies. Rather, we suggest recent review articles as entry points to the topics that are not adequately covered. Moreover, because studies on fungal VOC lag considerably behind those on bacterial VOC, we have allocated more space to the former in hopes of stimulating new research. We also discuss challenges in elucidating the ecological roles of microbial VOC and present potential opportunities for improving plant health through a systems understanding of the mechanisms underpinning VOC-mediated plant-microbe and microbemicrobe interactions.

\section{Microbial VOC as regulators}

of plant growth and stress resistance.

Diverse groups of bacteria and fungi are intimately associated with plants and their rhizosphere and affect the growth and fitness of plants by modulating processes such as pathogenesis, defense, tolerance to environmental stresses, and nutrient recycling and utilization (Buée et al. 2009; Khan et al. 2009; Saunders et al. 2010). Accordingly, plant-associated microbial communities play critical roles in the ecology of plants at both the individual and community levels (Bever et al. 2010; Inderjit and van der Putten 2010; Porras-Alfaro and Bayman 2011). However, with the exception of a few extensively studied microbes, such as nitrogen-fixing bacteria, mycorrhizal fungi, and major pathogens, the question of how many other microbes affect plants remains to be elucidated. Release of VOC is one of the mechanisms that certain microbes utilize to influence the growth and fitness of associated plants. Here, we review selected examples of how microbial VOC affect plants. Additional examples can be found in recent reviews (Bailly and Weisskopf 2012; Bennett et al. 2013; Wenke et al. 2012b).

VOC produced by several rhizobacterial species enhanced the growth or stress resistance of plants (Ryu et al. 2003).<smiles>c1ccc2scnc2c1</smiles>

Benzothiazole ${ }^{4}$<smiles>O=Cc1ccccc1</smiles>

benzaldehyde ${ }^{4}$<smiles>O=CCc1ccccc1</smiles>

phenylacetaldehyde ${ }^{4}$<smiles>OC1CCCCC1</smiles>

cyclohexanol ${ }^{4}$<smiles>CC(O)C(C)O</smiles>

2-ethyl-1-hexanol $4 \quad$ 2,3-butanediol ${ }^{1,2}$<smiles>O=C(O)CCc1ccccc1</smiles>

3-phenyproprionic acid ${ }^{3}$<smiles>CCCCCCCCCC=O</smiles><smiles>CCCCCCCCC=O</smiles>

n-decanal ${ }^{4}$

nonanal ${ }^{4}$

B<smiles></smiles>

beta-caryophylene ${ }^{1,2}$<smiles>CCCCCC(O)CC</smiles>

3-octanol 5,6<smiles>C/C1=C/CC/C(C)=C\CC(C)(C)/C=C/C1</smiles>

alpha-humulene ${ }^{4}$<smiles>C=C(CCC=C(C)C)[C@H]1CC[C@](C)(O)[C@@H]1C</smiles><smiles>CCCCO</smiles>

1-butanol 4

chokol K $\mathbf{K}^{4,6}$<smiles>CCCCCCCCC/C(C)=C\C(=O)OC</smiles>

Methyl (Z)-3-methyldodec-2-enoate ${ }^{6}$<smiles>CCCCC/C=C/C=O</smiles>

trans-2-octenal ${ }^{3}$<smiles>CCCCCC(=O)CC</smiles>

3-octanone ${ }^{5}$<smiles>C=CC(O)CCCCC</smiles>

1-octen-3-ol ${ }^{2,3,5,6}$<smiles>COC(C)=O</smiles>

methyl acetate ${ }^{4}$

Fig. 2. Structure of microbial volatile compounds with known effects on other organisms. Compounds produced by A, bacteria and B, fungi are noted along with their known and suspected functions. ${ }^{1}$ Plant growth enhancement, ${ }^{2}$ increased stress resistance, ${ }^{3}$ phytotoxicity, ${ }^{4}$ antimicrobial activity, ${ }^{5}$ signal for controlling the growth or development of itself or other microbes, and ${ }^{6}$ chemo-attractant. 
Comparison of VOC profiles, application of synthetic compounds, and bacterial mutants defective in producing candidate compounds suggested that 2,3-butanediol (Fig. 2) is a major VOC produced by Bacillus subtilis and B. amyloliquefaciens to mediate growth promotion in Arabidopsis thaliana (Farag et al. 2006; Ryu et al. 2003). Co-cultivation of $A$. thaliana with these Bacillus strains in the I plate, a partitioned petri dish that prevents their physical contact, also induced systemic resistance in A. thaliana against Erwinia carotovora, as did exogenous application of 2,3-butanediol (Ryu et al. 2004). Salt tolerance of $A$. thaliana was also increased by VOC from $B$. subtilis (Zhang et al. 2008a). In addition, isolates of other Bacillus spp., cultured from the rhizosphere of lemon plants, affected the growth and root architecture of A. thaliana via VOC production; however, the nature of responsible VOC remains unknown (Gutierrez-Luna et al. 2010). Pseudomonas chlororaphis also produced 2,3-butanediol and enhanced the growth of tobacco (Han et al. 2006). Its synthesis by $P$. chlororaphis requires the sensor kinase GacS (Han et al. 2006). Given that GacS controls the production of signal molecules such as the acyl-homoserine lactones, 2,3-butanediol and, potentially, other VOC may belong to a cache of chemical signals bacteria deploy to communicate with neighboring organisms. Among three stereoisomers of 2,3-butanediol, only 2R,3R-butanediol was effective in causing these phenotypes (Han et al. 2006), suggesting the presence of specific receptors for this isomer in plants. This compound increased resistance of tobacco against E. carotovora but not against $P$. syringae pv. tabaci (Han et al. 2006) and also enhanced drought tolerance in A. thaliana (Cho et al. 2008). Members of other bacterial genera that are associated with the rhizosphere, such as Burkholderia cepaci and Staphylococcus epidermidis, also produce VOC that promote the growth of $A$. thaliana, although the specific identity of the causal compounds remains unknown (Vespermann et al. 2007).

Not all bacterial volatiles positively affect plants. Members of several bacterial genera, including Burkholderia, Chromobacterium, Pseudomonas, Serratia, and Stenotrophomonas, produce several volatiles that inhibit plant growth or exhibit phytotoxicity (Bailly and Weisskopf 2012; Kai et al. 2009). Compounds that likely mediate these negative effects have been identified in a few bacteria and include ammonia, dimethyldisulfide, hydrogen cyanide $(\mathrm{HCN})$, and 3-phenylpropionic acid (Blom et al. 2011b). Interestingly, certain soil bacterial pathogens might use VOC as effectors to suppress host defense responses (Blom et al. 2011a).

By taking advantage of resources available for A. thaliana, the mechanisms underpinning bacterial VOC-mediated effects have been studied. Growth responses of A. thaliana mutants, defective in one or more hormonal signaling pathway, to Bacillus VOC showed that some mutants (ein2 and cre1) responded to VOC from B. subtilis but not those from B. amyloliquefaciens (Ryu et al. 2003). Similarly, induced resistance against E. carotovora by $B$. subtilis VOC required an ethylene-dependent signaling pathway but this pathway was not needed for $B$. amyloliquefaciens VOC (Ryu et al. 2004). Drought tolerance caused by $P$. chlororaphis VOC and 2R,3R-butanediol seems to require the salicylic acid, jasmonic acid (JA), and ethylene signaling pathways (Cho et al. 2008). Decreased stomatal aperture induced by $2 \mathrm{R}, 3 \mathrm{R}$-butanediol, thus reducing water loss, appears to contribute to this phenotype (Cho et al. 2008, 2012). These mutant studies suggest that different strains produce different blends of VOC, consequently requiring different combinations of plant signaling pathways to mediate their effect. Transgenic $A$. thaliana lines expressing $\beta$-glucuronidase (GUS) under the promoters that respond to specific hormones have been employed to determine the spatial and temporal activation pattern of individual hormonal signaling pathways by Bacillus VOC, which complemented the mutant studies in evaluating the role of these pathways (Ryu et al. 2004; Zhang et al. 2007). Expression patterns of the genes involved in auxin synthesis, transgenic lines containing GUS driven by a promoter responding to auxin, and plant responses to the auxin transporter inhibitor 1-naphthylphthalamic acid suggest that regulation of auxin homeostasis by VOC is critical for growth promotion (Zhang et al. 2007). However, the involvement of other hormones could not be ruled out. Most of the A. thaliana genes that are differentially expressed in response to $B$. subtilis VOC (approximately 600) appear to function in cell wall modification, metabolism, stress responses, or hormone regulation (Zhang et al. 2007). A combination of proteome analysis, reverse-transcriptase polymerase chain reaction, and measurement of the activity of antioxidant enzymes also suggested a number of molecular changes potentially underpinning growth promotion of $A$. thaliana by $B$. subtilis VOC (Kwon et al. 2010). These VOC augmented the efficiency of photosynthesis and chlorophyll content in A. thaliana by modulating endogenous sugar and abscisic acid signaling, thus supplying resources needed for enhanced plant growth (Zhang et al. 2008b). Increased salt tolerance conferred by $B$. subtilis VOC requires $H K T 1$, an A. thaliana gene encoding a high-affinity $\mathrm{Na}^{+}$transporter (Zhang et al. 2008a). Analysis of its expression pattern suggested tissue-specific regulation as a potential mechanism underlying this effect (Zhang et al. 2008a). Under salt stress $(100 \mathrm{mM} \mathrm{NaCl})$ in A. thaliana exposed to B. subtilis VOC, $H K T 1$ was downregulated in roots but upregulated in shoots, resulting in lower overall $\mathrm{Na}^{+}$accumulation than that in control plants (Zhang et al. 2008a). Little is known about how certain volatiles stunt or kill plants. Oxidative stress caused by $\mathrm{HCN}$, which is produced by a few species, appears to underlie its phytotoxicity (Blom et al. 2011b). Molecular responses of A. thaliana to growth-inhibiting VOC from Serratia plymuthica and Stenotrophomonas maltophilia suggest that one of the WRKY transcription factors, WRKY18, plays a critical role in mediating growth inhibition (Wenke et al. 2012a).

Many plant-associated fungi influence plant processes (Porras-Alfaro and Bayman 2011; Saunders et al. 2010). However, whether fungal VOC play any significant physiological roles in plants remains mostly unknown. Several Trichoderma spp. have been extensively studied and commercially utilized because of their ability to compete effectively against pathogenic soil microbes and enhance certain plant performances (Harman 2011; Lorito et al. 2010). Similar to what has been observed in A. thaliana treated with certain bacterial VOC, $A$. thaliana exposed to unknown VOC produced by $T$. viride grew taller and bigger, flowered earlier, and had more lateral roots and chlorophylls (Hung et al. 2013). Treatment with 1-octen3 -ol, a VOC commonly produced by fungi through enzymatic modifications of linoleic acid, was shown to induce the expression of several genes under the control of the JA/ethylenedependent pathogen or wound defense signaling pathway in $A$. thaliana (Kishimoto et al. 2007). Consistent with the gene expression pattern, treated plants exhibited increased resistance against the necrotropic fungal pathogen Botrytis cinerea, suggesting that plants may have evolved to recognize certain fungal VOC as microbe-associated molecular patterns. Unidentified VOC from Alternaria alternata, Penicillium charlesii, and $P$. aurantiogriseum promoted the accumulation of starch in leaves of several plant species as well as their growth (Ezquer et al. 2010). However, it is not clear as to how the modulation of starch metabolism influences their interactions with plants. Fusarium oxysporum is a soilborne fungal species complex that often resides in the rhizosphere of diverse plants, includes vascular wilt pathogens of $>100$ plant species, and can also be 
saprophytic. A nonpathogenic strain of $F$. oxysporum, MSA35, protects plants from pathogenic $F$. oxysporum isolates and is associated with a group of ectosymbiotic bacterial species (Minerdi et al. 2009, 2011). This strain enhanced the growth of lettuce via VOC production (Minerdi et al. 2011). When its symbiotic bacteria had been cured by serially culturing MSA35 in a medium amended with antibiotics, the cured strain could no longer promote plant growth (Minerdi et al. 2011). Comparison of VOC produced by MSA35 and the cured strain showed a difference in the production of some sesquiterpenes (Minerdi et al. 2009). Lettuce seedlings treated with $\beta$-caryophyllene (Fig. 2), one of the sesquiterpenes produced by MSA35, displayed phenotypes similar to those exposed to VOC from MSA35 (Minerdi et al. 2011). In contrast, VOC produced by fruiting bodies of the ectomycorrhizal truffles Tuber borchii, T. indicum, and T. melanopsorum inhibited root development and foliar growth of Arabidopsis thaliana and their host Cistus incanus and, in some cases, caused phytotoxicity (Splivallo et al. 2007). When 10 main truffle VOC tested individually, most of them negatively affected the seed germination, primary root elongation, and leaf growth of $A$. thaliana. In-depth analyses with two VOC, 1-octen-3-ol and trans2-octenal, suggested that modification of the oxidative metabolism by these VOC might underlie the negative effects on growth (Splivallo et al. 2007).

Given the vast diversity of microbes in and around plants, the number of bacterial and fungal species that have been analyzed for the production of VOC that affect plants is grossly inadequate. Furthermore, the focus of most previous surveys has been on those dwelling in soils, especially the rhizosphere. A systematic survey of microbial communities associated with diverse plants in different ecosystems, including those associated with aboveground parts of plant (e.g., endophytes and phyllosphere microbes), is needed to advance our understanding of the evolution and roles of microbial VOC in modulating plant growth and fitness.

\section{Microbial VOC as chemical weapons against other microbes.}

Most microbes reside in their ecological niches in close association with other organisms. The structure and emergent properties of such communities are intimately linked to how their members interact with each other and the environment (Konopka 2009). Competition for nutrients and space probably is the most common form of interaction and often leads to a chemical warfare, in which competing members secrete a diverse array of proteins and compounds to suppress or kill the others. Some bacteria and fungi that are well equipped with such weapons have been exploited as biocontrol agents to manage plant pathogens (Pal and McSpadden Gardener 2007). A main motivation that has driven studies on antimicrobial VOC is the potential utility of VOC and their producers as novel agents for pathogen control. Synthetic and plant-derived VOC already have been extensively utilized to manage insect pests (Thacker and Train 2010). However, although the exploration of antimicrobial VOC started decades ago (McCain 1966), this field still is in its infancy because most studies have focused on discovery, with little known about how antimicrobial VOC affect target microbes.

VOC produced by several bacteria have been shown to inhibit spore germination and mycelial growth or cause abnormal morphological changes in fungi (Effmert et al. 2012). Among 197 bacterial strains cultured from canola and soybean plants, 14 of them, most of which belong to four Pseudomonas spp., consistently produced VOC that inhibited germination of sclerotia and ascospores or mycelial growth of Sclerotinia sclerotiorum, a major fungal pathogen of these plants, in vitro and in soil tests (Fernando et al. 2005). Among the 23 volatiles from these isolates, benzothiazole, cyclohexanol, n-decanal, dimethyltrisulfide, 2-ethyl-1-hexanol, and nonanal (Fig. 2) completely inhibited mycelial growth and sclerotial germination. None of the 14 isolates produced all six compounds, indicating that different strains produce different combinations of common and strain- or species-specific antifungal volatiles. A more extensive survey involving 1,018 bacterial isolates showed that VOC from 328 isolates, which belong to families Alcaligenaceae, Bacillales, Micrococcaceae, Rhizobiaceae, and Xanthomonadaceae, inhibited spore germination and mycelial growth of two nematicidal fungi (Zou et al. 2007). Seven VOC, including acetamide, benzaldehyde, benzothiazole, 1butanamine, methanamine, phenylacetaldehyde, and 1-decene, appear to play roles in fungistasis. Benzothiazole was the only VOC that was found in both surveys, suggesting that different species produce different VOC for fungistasis, antifungal activity of many compounds are target specific, or a combination of both. Although alterations in enzyme activities or gene expression in fungi have been observed upon exposure to certain bacterial VOC in several studies (Effmert et al. 2012), the question of what molecular changes underpin fungistasis has not been clearly answered.

Not surprisingly, fungi also produce VOC exhibiting antibacterial or anti-fungal activity. Some of the VOC produced by the oyster mushroom Pleurotus ostreatus inhibited the growth of several bacterial species at concentrations found in its fruit body (Beltran-Garcia et al. 1997). Fungal endophytes confer multiple fitness benefits, including enhanced resistance to biotic and abiotic stresses (Porras-Alfaro and Bayman 2011), but the underlying mechanisms are poorly understood. Certain endophytes produce antimicrobial VOC which may directly contribute to defense against pathogens. Chokol K, a VOC produced by the grass endophyte Epichlö sp., inhibited the growth and spore germination of two mycoparasites associated with stromata, the fruiting structure of Epichlö̈ spp., and two plant-pathogenic fungi (Steinebrunner et al. 2008a). Muscodor albus, a fungal endophyte originally isolated from cinnamon tree, emits a mixture of VOC that inhibit or kill a broad range of bacteria, fungi, and oomycetes (Strobel et al. 2001). Analysis of its VOC via GC-MS and bioassays with identified compounds led to the identification of many antimicrobial VOC, with 1-butanol and 3-methyl-acetate being most effective (Strobel 2006a; Strobel et al. 2001). However, none was lethal to the testers individually, suggesting that Muscodor VOC work synergistically or additively (Strobel, 2006a). Additional $M$. albus isolates and related species, some of which exhibit similar VOC-mediated antimicrobial activities, have been isolated (Strobel 2006b; Zhang et al. 2010). The potential of $M$. albus and its VOC as biofumigants for controlling plant pathogens, human pathogens, and post-harvest pathogens has been demonstrated (Mercier and Smilanick 2005; Ramin et al. 2005; Strobel et al. 2001).

Some biocontrol fungi appear to employ VOC to control pathogenic fungi (Bruce et al. 2003; Humphris et al. 2002; Hynes et al. 2007). Members of the genus Trichoderma have been shown to effectively parasitize or inhibit a wide range of soilborne fungal pathogens by employing multiple mechanisms, such as mycoparasitism, nutrient competition, and secretion of inhibitory compounds and hydrolytic enzymes (Harman 2011; Lorito et al. 2010). Trichoderma viride and T. aureoviride emitted VOC that inhibit the growth and protein production of Serpula lacrymans, a wood-rotting basidiomycete. However, T. pseudokoningii had no effect on any of the Serpula isolates tested, suggesting the species-specific nature of antifungal VOC production (Humphris et al. 2002). Similarly, the degree of growth inhibition of $F$. oxysporum $\mathrm{f}$. sp. ciceris, a 
soilborne fungal pathogen that causes chickpea wilt, by VOC produced by multiple isolates of three Trichoderma spp. also varied depending on the combination of the Trichoderma and F. oxysporum f. sp. ciceris isolates tested (Dubey et al. 2007). F. oxysporum strain MSA35, which enhanced lettuce growth via VOC (Minerdi et al. 2011), also produces VOC that inhibit the growth of pathogenic strains of $F$. oxysporum, and the production of these antifungal VOC requires the presence of ectosymbiotic bacteria (Minerdi et al. 2009). Although the VOC contributing to Trichoderma spp.'s biocontrol activity have not yet been identified, $\alpha$-humulene (Fig. 2), a sesquiterpene emitted by MSA35, but not MSA35 cured of its symbiotic bacteria, was shown to inhibit mycelial growth and downregulate the expression of several virulence genes in pathogenic $F$. oxysporum strains, supporting its involvement in biocontrol (Minerdi et al. 2009).

\section{Fungal VOC as signals mediating intra- and interspecies communications.}

Some microbial VOC are utilized for dialog rather than warfare. Just as bacteria coordinate their activities in their communities via chemical signals (e.g., quorum sensing via the use of $\mathrm{N}$-acyl homeserine lactone), fungi also use diverse chemical signals, some of which are volatile, to control processes critical to their ecology and reproduction such as nutrient acquisition, sporulation, spore germination, and sexual development (Bennett et al. 2013; Leeder et al. 2011). Accordingly, VOC that affect such processes control the structure and emergent properties of the microbial communities associated with plants, thus influencing the plant health and fitness both directly and indirectly. One well-known form of communication occurs when too many spores exist in proximity. Under such conditions, fungi suppress spore germination through the use of self-inhibitors (a phenomenon known as the "crowding effect"), probably to enhance the likelihood of survival and proliferation upon germination. Penicillium paneum employs 1-octen-3-ol (Fig. 2), a VOC commonly produced by many other fungi, to control conidial germination in a reversible manner (Chitarra et al. 2004, 2005). This VOC was shown to inhibit germ-tube formation, alter the intracellular $\mathrm{pH}$, increase the permeability of the membrane, and alter protein expression (Chitarra et al. 2005). In Trichoderma spp., 1-octen-3-ol and its analogs 3-octanol and 3-octanone (Fig. 2) appear to participate in controlling conidiation in a concentration-dependent manner (Nemcovic et al. 2008). Conidiating colonies of Trichoderma spp. produced these VOC and induced conidiation in neighboring colonies even in the absence of light, a known inducer of conidiation, suggesting that certain VOC may act as fungal "hormones" and control fungal development (Leeder et al. 2011).

Many fungi rely on insects for dispersing their spores, a service critical for secondary colonization, disease development, and sexual development, and some of these fungi produce VOC mimicking those produced by flowers to attract pollinator insects (Bruce et al. 2005; Dudareva et al. 2006; Roy 1993). This mimicry also works in the opposite direction, because certain flowering plants produce VOC that mimic the scent of mushroom fruiting bodies to attract insects (Kaiser 2006). The heterothallic mating system of the grass endophytic Epichloë sp. relies on Botanophila flies for transferring gametic spores from grasses colonized by strains of the opposite mating type to stromata. Analysis of VOC produced by stromata of five Epichlö spp. and field bioassays using synthetic compounds led to the identification of two compounds, methyl ( $Z$ )-3-methyldodec-2-enoate (Steinebrunner et al. 2008b) and chokol K (Schiestl et al. 2006; Steinebrunner et al. 2008b) as major attractants. Both compounds elicit re- sponses in the fly olfactory system (Steinebrunner et al. 2008b). Other fungal VOC, such as 1-3-octanol, 1-octen-3-ol, and octan-1-ol (Fig. 2), also have been shown to attract insects (Faldt et al. 1999).

\section{Synthesis: biological and ecological roles of microbial VOC represent a mostly uncharted frontier that awaits systematic explorations.}

Given the large number of VOC identified from the limited number of microbial species surveyed to date (Effmert et al. 2012; Kramer and Abraham 2012; Schulz and Dickschat 2007), we have observed only a glimpse of this chemical ecology frontier. Not only are many novel VOC and their functions waiting to be discovered but known VOC also are likely to have hitherto unrecognized biological and ecological roles, some of which may offer novel solutions for managing agricultural and environmental problems. Systematic exploration of microbes in diverse ecosystems, in combination with their phylogenetic contexts, will help us to develop hypotheses concerning the evolution, function, and ecological roles of VOC production in microbes. Microbial culture collections, especially those associated with detailed genotypic and phenotypic data, offer readily available materials for comprehensive survey of VOC in specific taxa. Resulting data not only will advance our understanding of critical ecosystem processes and services but also will assist in developing novel means for controlling agricultural and environmental problems via the use of beneficial microbes.

Multiple indicators that are associated with the composition and activity of microbial communities have been employed to study how these communities impact ecosystems and how changing environmental conditions or human activities have impacted them. McNeal and Herbert (2009) proposed the utility of VOC as potential indicators to assess the status of soil microbial communities over large spatiotemporal dynamics and environmental perturbations (McNeal and Herbert 2009). As our understanding of how various microbial VOC affect ecosystems and their constituents increases, the accuracy and value of VOC profiles as such indicators will likely improve. Versatile application of plant-derived VOC such as neem oil and Chrysanthemum monoterpenes in controlling pests is well established (Thacker and Train 2010). Metabolic engineering of plants or plant-associated microbes to produce VOC with fumigant activity may work as an alternative to traditional chemical control of pests. Microbial VOC-mediated growth promotion and stress resistance in plants (Farag et al. 2006; Gutierrez-Luna et al. 2010; Han et al. 2006; Kwon et al. 2010; Minerdi et al. 2009; Ryu et al. 2003, 2004; Zhang et al. $2008 \mathrm{a}, \mathrm{b})$ suggest that certain microbes and their VOC could be deployed to alleviate the heavy dependence of crop production on chemical input. The short-lived "pesticide revolution," caused by the rapid selection and spread of pesticide-resistant insects, and the emergence of resistance to chemicals that control weeds and microbial pathogens has created a boom-andbust cycle (Lewis et al. 1997). Plant breeding programs for disease resistance and chemical controls mostly neglect microbial partners and unknowingly may destroy this critical partnership. In order to feed the increasing world population without severely degrading the environment, we need to explore alternative or complementary solutions to current practices. Restoring or fortifying key plant-microbe partnerships would make crop plants rely less on human intervention; this strategy is particularly critical for resource-limited subsistence farming.

Several major pitfalls and challenges face researchers who seek to illuminate the roles and potential applications of microbial VOC. VOC-producing organisms emit many different compounds simultaneously, and the composition of produced VOC 
is highly dynamic and likely influenced by multiple factors, such as nutrient and oxygen availability and the physiological state of the VOC producer (Insam and Seewald 2010). Accordingly, phenotypes in a tester organism may vary depending on how bacteria or fungi are cultured. Furthermore, individual VOC are likely to work synergistically or antagonistically with other VOC to affect target organisms, suggesting that, under certain experimental conditions, VOC that cause opposite effects may cancel out each other's effect and fail to cause notable phenotypes. Although evaluating identified VOC individually using their synthetic versions is a potential solution, this approach may miss VOC combinations that work synergistically. Although it probably is not practical to employ experimental designs that address all these potential pitfalls, employment of multiple well-controlled experimental conditions is critical in order not to miss too many potentially important VOC and their biological effects.

Two studies (Blom et al. 2011a; Kai and Piechulla 2009) further underscored the importance of proper experimental design and appropriate controls to accurately evaluate the role of microbial VOC in modulating plant growth and other important traits. Because increased $\mathrm{CO}_{2}$ resulting from microbial catabolism in a closed assay system such as the I plate will enhance plant growth, negative effects of certain VOC may be masked and the degree of growth enhancement by other VOC will likely be inflated (Kai and Piechulla 2009). A survey of soil bacteria for their ability to affect the growth of $A$. thaliana revealed the critical importance of culture conditions in their VOC production (Blom et al. 2011a). Depending on the culture medium used and the inoculum density, the same strains caused opposite effects on the plants exposed to their VOC ranging from death to sixfold increase in biomass, suggesting that culture conditions significantly modulated their VOC profiles, including the type and amount of compounds (Blom et al. 2011a). This study underscores the importance of studying potential roles of microbial VOC in consideration of factors that can potentially affect VOC production.

In nature, organisms near and far are potential targets for microbial VOC, and the same VOC may perform disparate functions in many different organisms, making it difficult to choose appropriate target organisms and assay conditions for uncovering functions. However, potential clues can be found in known biological traits and ecological niches of individual microbial species and their relatives, because it is likely that the production of specific VOC is linked to the biology and ecology of individual species. For example, in discovering functions for VOC commonly produced by microbes that are closely associated with specific plants, obvious targets for evaluating their functions are host plants and other organisms associated with the host plants. The multifaceted effects of individual VOC compounds and their differential functions, depending on environmental factors and target organisms, also potentially complicate the elucidation of their roles. A good example is the common fungal volatile 1-octen-3-ol, which has been shown to affect insects (Faldt et al. 1999), plants (Kishimoto et al. 2007), and fungi (Chitarra et al. 2004). When scientists within a given subdiscipline focus on a narrow set of observable changes and potential targets, we run the risk of failing to recognize important roles and can potentially skew our view on VOC functions.

Despite these challenges, microbial VOC-mediated signaling is a potential gold mine we should explore. Model microbes and plants with rich resources and accumulated knowledge will help overcome some of the experimental challenges. As reviewed above, studies in the model plant A. thaliana have been instrumental in elucidating the function and mechanism of action of VOC from both bacteria and fungi. This model plant will continue to facilitate systematic screening of diverse microbes for their ability to affect plants via VOC production and subsequent studies on underlying mechanisms, thus serving as a stepping stone for parallel studies on economically important plants. However, because A. thaliana may not respond to certain VOC that otherwise affect other plants, the importance of developing additional model plants cannot be overlooked. Another key consideration is balancing laboratory and field studies. Technological advances with respect to profiling and analyzing VOC; genome sequencing and functional genomics tools; and tools for studying the molecular, physiological, and cellular changes in plant and microbial systems no doubt will accelerate studies on the biosynthesis and modes of action of microbial VOC. Finally, we must remember that, despite their enormous reductionist value, such molecular approaches cannot substitute for field experiments that evaluate the roles of VOC and their producers under natural ecological settings. Advancement of our fundamental understanding as well as the development and deployment of VOC-based solutions for agricultural and environmental problems will require approaches at many levels.

\section{ACKNOWLEDGMENTS}

We thank the Penn State College of Agricultural Sciences and Rutgers University for their support; D. Whalen, J. Demers, and N. Naranjo for help with manuscript preparation; R. Hung and S. Lee for providing useful input to our thinking about the ecological roles of fungal VOC; and three anonymous reviewers and the editor of this review for their critical suggestions and instrumental help in improving this review.

\section{LITERATURE CITED}

Bailly, A. 1., and Weisskopf, L. 2012. The modulating effect of bacterial volatiles on plant growth: Current knowledge and future challenges. Plant Signal. Behav. 7:79-85.

Baldwin, I. T. 2010. Plant volatiles. Curr. Biol. 20:392-397.

Bednarek, P., Kwon, C., and Schulze-Lefert, P. 2010. Not a peripheral issue Secretion in plant-microbe interactions. Curr. Opin. Plant Biol. 13:378387.

Beltran-Garcia, M. J., Estarron-Espinosa, M., and Ogura, T. 1997. Volatile compounds secreted by the oyster mushroom (Pleurotus ostreatus) and their antibacterial activities. J. Agric. Food. Chem. 45:4049-4052.

Bennett, J. W., Hung, R., Lee, S., and Padhi, S. 2013. Fungal and bacterial volatile organic compounds: An overview and their role as ecological signaling agents. Pages 373-393 in: The Mycota IX Fungal Interactions. B. Hock, ed. Springer, Berlin

Berendsen, R. L., Pieterse, C. M. J., and Bakker, P. A. H. M. 2012. The rhizosphere microbiome and plant health. Trends Plant Sci. 17:478-486.

Bever, J. D., Dickie, I. A., Facelli, E., Facelli, J. M., Klironomos, J., Moora, M., Rillig, M. C., Stock, W. D., Tibbett, M., and Zobel, M. 2010. Rooting theories of plant community ecology in microbial interactions. Trends Ecol. Evol. 25:468-478.

Blom, D., Fabbri, C., Connor, E. C., Schiestl, F. P., Klauser, D. R., Boller T., Eberl, L., and Weisskopf, L. 2011a. Production of plant growth modulating volatiles is widespread among rhizosphere bacteria and strongly depends on culture conditions. Environ. Microbiol. 13:3047-3058.

Blom, D., Fabbri, C., Eberl, L., and Weisskopf, L. 2011b. Volatile-mediated killing of Arabidopsis thaliana by bacteria is mainly due to hydrogen cyanide. Appl. Environ. Microbiol. 77:1000-1008.

Bonfante, P., and Anca, I. A. 2009. Plants, mycorrhizal fungi, and bacteria: A network of interactions. Annu. Rev. Microbiol. 63:363-383.

Bruce, A., Stewart, D., Verrall, S., and Wheatley, R. E. 2003. Effect of volatiles from bacteria and yeast on the growth and pigmentation of sapstain fungi. Int. Biodeterior. Biodegrad. 51:101-108.

Bruce, T. J. A., Wadhams, L. J., and Woodcock, C. M. 2005. Insect host location: A volatile situation. Trends Plant Sci. 10:269-274.

Buée, M., De Boer, W., Martin, F., van Overbeek, L., and Jurkevitch, E. 2009. The rhizosphere zoo: An overview of plant-associated communities of microorganisms, including phages, bacteria, archaea, and fungi, and of some of their structuring factors. Plant Soil 321:189-212.

Cheng, S. S., Lin, H. Y., and Chang, S. T. 2005. Chemical composition and antifungal activity of essential oils from different tissues of Japanese 
cedar (Cryptomeria japonica). J. Agric. Food. Chem. 53:614-619.

Chitarra, G. S., Abee, T., Rombouts, F. M., Posthumus, M. A., and Dijksterhuis, J. 2004. Germination of Penicillium paneum conidia is regulated by 1-octen-3-ol, a volatile self-inhibitor. Appl. Environ. Microbiol. 70:2823-2829.

Chitarra, G. S., Abee, T., Rombouts, F. M., and Dijksterhuis, J. 2005. 1octen-3-ol inhibits conidia germination of Penicillium paneum despite of mild effects on membrane permeability, respiration, intracellular $\mathrm{pH}$, and changes the protein composition. FEMS (Fed. Eur. Microbiol. Soc.) Microbiol. Ecol. 54:67-75.

Cho, S. M., Kang, B. R., Han, S. H., Anderson, A. J., Park, J. Y., Lee, Y. H., Cho, B. H., Yang, K. Y., Ryu, C. M., and Kirn, Y. C. 2008. 2R,3Rbutanediol, a bacterial volatile produced by Pseudomonas chlororaphis O6, is involved in induction of systemic tolerance to drought in Arabidopsis thaliana. Mol. Plant-Microbe Interact. 21:1067-1075.

Cho, S. M., Kang, B. R., Kim, J. J., and Kim, Y. C. 2012. Induced systemic drought and salt tolerance by Pseudomonas chlororaphis $\mathrm{O} 6$ root colonization is mediated by ABA-independent stomatal closure. Plant Pathol. J. 28:202-206.

Clavijo-McCormick, A., Unsicker, S. B., and Gershenzon, J. 2012. The specificity of herbivore-induced plant volatiles in attracting herbivore enemies. Trends Plant Sci. 17:303-310.

Dubey, S. C., Suresh, M., and Singh, B. 2007. Evaluation of Trichoderma species against Fusarium oxysporum $\mathrm{f}$. sp. ciceris for integrated management of chickpea wilt. Biol. Control 40:118-127.

Dudareva, N., Negre, F., Nagegowda, D. A., and Orlova, I. 2006. Plant volatiles: Recent advances and future perspectives. Crit. Rev. Plant Sci. $25: 417-440$

Effmert, U., Kalderás, J., Warnke, R., and Piechulla, B. 2012. Volatile mediated interactions between bacteria and fungi in the soil. J. Chem. Ecol. 38:665-703.

Ezenwa, V. O., Gerardo, N. M., Inouye, D. W., Medina, M. N., and Xavier J. B. 2012. Animal behavior and the microbiome. Science 338:198-199.

Ezquer, I., Li, J., Ovecka, M., Baroja-Fernandez, E., Munoz, F. J., Montero, M., de Cerio, J. D., Hidalgo, M., Sesma, M. T., Bahaji, A., Etxeberria, E., and Pozueta-Romero, J. 2010. Microbial volatile emissions promote accumulation of exceptionally high levels of starch in leaves in monoand dicotyledonous plants. Plant Cell Physiol. 51:1674-1693.

Faldt, J., Jonsell, M., Nordlander, G., and Borg-Karlson, A. K. 1999. Volatiles of bracket fungi Fomitopsis pinicola and Fomes fomentarius and their functions as insect attractants. J. Chem. Ecol. 25:567-590.

Farag, M. A., Ryu, C.-M., Sumner, L. W., and Pare, P. W. 2006. GC-MS SPME profiling of rhizobacterial volatiles reveals prospective inducers of growth promotion and induced systemic resistance in plants. Phytochemistry 67:2262-2268

Fernando, W. G. D., Ramarathnam, R., Krishnamoorthy, A. S., and Savchuk, S. C. 2005. Identification and use of potential bacterial organic antifungal volatiles in biocontrol. Soil Biol. Biochem. 37:955-964.

Gutierrez-Luna, F. M., Lopez-Bucio, J., Altamirano-Hernandez, J., ValenciaCantero, E., de la Cruz, H. R., and Macias-Rodriguez, L. 2010. Plant growth-promoting rhizobacteria modulate root system architecture in Arabidopsis thaliana through volatile organic compound emission. Symbiosis 51:75-83.

Han, S. H., Lee, S. J., Moon, J. H., Park, K. H., Yang, K. Y., Cho, B. H., Kim, K. Y., Kim, Y. W., Lee, M. C., Anderson, A. J., and Kim, Y. C. 2006. GacS-dependent production of 2R,3R-butanediol by Pseudomonas chlororaphis $\mathrm{O} 6$ is a major determinant for eliciting systemic resistance against Erwinia carotovora but not against Pseudomonas syringae pv. tabaci in tobacco. Mol. Plant-Microbe Interact. 19:924-930

Harman, G. 2011. Trichoderma - not just for biocontrol anymore. Phytoparasitica 39:103-108.

Heil, M., and Karban, R. 2010. Explaining evolution of plant communication by airborne signals. Trends Ecol. Evol. 25:137-144.

Herrmann, A., ed. 2010. The Chemistry and Biology of Volatiles. John Wiley \& Sons, Chichester, U.K.

Humphris, S. N., Bruce, A., Buultjens, E., and Wheatley, R. E. 2002. The effects of volatile microbial secondary metabolites on protein synthesis in Serpula lacrymans. FEMS (Fed. Eur. Microbiol. Soc.) Microbiol. Lett. 210:215-219.

Hung, R., Lee, S., and Bennett, J. W. 2013. Arabidopsis thaliana as a model system for testing the effect of Trichoderma volatile organic compounds. Fungal Ecol. 6:19-26.

Hynes, J., Müller, C., Jones, T., and Boddy, L. 2007. Changes in volatile production during the course of fungal mycelial interactions between Hypholoma fasciculare and Resinicium bicolor. J. Chem. Ecol. 33:4357.

Inderjit, and van der Putten, W. H. 2010. Impacts of soil microbial communities on exotic plant invasions. Trends Ecol. Evol. 25:512-519.

Insam, H., and Seewald, M. S. A. 2010. Volatile organic compounds
(VOC) in soils. Biol. Fertil. Soils 46:199-213.

Kai, M., and Piechulla, B. 2009. Plant growth promotion due to rhizobacterial volatiles-An effect of $\mathrm{CO}_{2}$ ? FEBS (Fed. Eur. Biochem. Soc.) Lett. 583:3473-3477.

Kai, M., Haustein, M., Molina, F., Petri, A., Scholz, B., and Piechulla, B. 2009. Bacterial volatiles and their action potential. Appl. Microbiol. Biotechnol. 81:1001-1012.

Kaiser, R. 2006. Flowers and fungi use scents to mimic each other. Science 311:806-807.

Kant, M. R., Bleeker, P. M., Van Wijk, M., Schuurink, R. C., and Haring, M. A. 2009. Plant volatiles in defence. Pages 613-666 in: Plant Innate Immunity, Academic Press, London.

Khan, M. S., Zaidi, A., Wani, P. A., Ahemad, M., and Oves, M. 2009. Functional diversity among plant growth-promoting rhizobacteria: Current status microbial strategies for crop improvement. Pages 105-132 in: Microbial Strategies for Crop Improvement. M. S. Khan, A. Zaidi, and J. Musarrat, eds. Springer, Berlin.

Kishimoto, K., Matsui, K., Ozawa, R., and Takabayashi, J. 2007. Volatile 1-octen-3-ol induces a defensive response in Arabidopsis thaliana. J. Gen. Plant Pathol. 73:35-37.

Konopka, A. 2009. What is microbial community ecology? ISME J. 3:1223-1230

Kordali, S., Kotan, R., Mavi, A., Cakir, A., Ala, A., and Yildirim, A. 2005. Determination of the chemical composition and antioxidant activity of the essential oil of Artemisia dracunculus and of the antifungal and antibacterial activities of Turkish Artemisia absinthium, A. dracunculus, Artemisia santonicum, and Artemisia spicigera essential oils. J. Agric. Food Chem. 53:9452-9458

Kramer, R., and Abraham, W.-R. 2012. Volatile sesquiterpenes from fungi: What are they good for? Phytochem. Rev. 11:15-37.

Kwon, Y. S., Ryu, C. M., Lee, S., Park, H. B., Han, K. S., Lee, J. H., Lee, K., Chung, W. S., Jeong, M. J., Kim, H. K., and Bae, D. W. 2010. Proteome analysis of Arabidopsis seedlings exposed to bacterial volatiles. Planta 232:1355-1370

Leeder, A. C., Palma-Guerrero, J., and Glass, N. L. 2011. The social network: Deciphering fungal language. Nat. Rev. Microbiol. 9:440-451.

Lewis, W. J., vanLenteren, J. C., Phatak, S. C., and Tumlinson, J. H. 1997. A total system approach to sustainable pest management. Proc. Natl. Acad. Sci. U.S.A. 94:12243-12248.

Lorito, M., Woo, S. L., Harman, G. E., and Monte, E. 2010. Translational research on Trichoderma: From 'omics to the field. Annu. Rev. Phytopathol. 48:395-417.

Lundberg, D. S., Lebeis, S. L., Paredes, S. H., Yourstone, S., Gehring, J., Malfatti, S., Tremblay, J., Engelbrektson, A., Kunin, V., del Rio, T. G., Edgar, R. C., Eickhorst, T., Ley, R. E., Hugenholtz, P., Tringe, S. G., and Dangl, J. L. 2012. Defining the core Arabidopsis thaliana root microbiome. Nature 488:86-90.

Martin, F., and Kamoun, S., eds. 2012. Effectors in Plant-Microbe Interactions. Wiley-Blackwell, Oxford.

McCain, A. H. 1966. A volatile antibiotic produced by Streptomyces griseus. (Abstr.) Phytopathology 56:150.

McNeal, K. S., and Herbert, B. E. 2009. Volatile organic metabolites as indicators of soil microbial activity and community composition shifts. Soil Sci. Soc. Am. J. 73:579-588.

Mercier, J., and Smilanick, J. L. 2005. Control of green mold and sour rot of stored lemon by biofumigation with Muscodor albus. Biol. Control 32:401-407.

Minerdi, D., Bossi, S., Gullino, M. L., and Garibaldi, A. 2009. Volatile organic compounds: A potential direct long-distance mechanism for antagonistic action of Fusarium oxysporum strain MSA 35. Environ. Microbiol. 11:844-854

Minerdi, D., Bossi, S., Maffei, M. E., Gullino, M. L., and Garibaldi, A. 2011. Fusarium oxysporum and its bacterial consortium promote lettuce growth and expansin A5 gene expression through microbial volatile organic compound (MVOC) emission. FEMS (Fed. Eur. Microbiol. Soc.) Microbiol. Ecol. 76:342-351.

Morath, S., Hung, R., and Bennett, J. W. 2012. Fungal volatile organic compounds: A review with emphasis on their biotechnological potential. Fungal Biol. Rev. 30:1-11.

Nemcovic, M., Jakubikova, L., Viden, I., and Farkas, V. 2008. Induction of conidiation by endogenous volatile compounds in Trichoderma spp. FEMS (Fed. Eur. Microbiol. Soc.) Microbiol. Lett. 284:231-236.

Pal, K. K., and McSpadden Gardener, B. 2007. Biological control of plant pathogens. The Plant Health Instructor. doi: 10.1094/PHI-A-20061117-02. Published online.

Porras-Alfaro, A., and Bayman, P. 2011. Hidden fungi, emergent properties: Endophytes and microbiomes. Annu. Rev. Phytopathol. 49:291-315.

Ramin, A. A., Braun, P. G., Prange, R. K., and DeLong, J. M. 2005. In vitro effects of Muscodor albus and three volatile components on growth of 
selected postharvest microorganisms. HortScience 40:2109-2114.

Reaves, M.-L., and Rabinowitz, J. D. 2011. Metabolomics in systems microbiology. Curr. Opin. Biotechnol. 22:17-25.

Robert-Seilaniantz, A., Grant, M., and Jones, J. D. G. 2011. Hormone crosstalk in plant disease and defense: More than just jasmonate-salicylate antagonism. Annu. Rev. Phytopathol. 49:317-343.

Roy, B. A. 1993. Floral mimicry by a plant pathogen. Nature 362:56-58.

Ryu, C.-M., Farag, M. A., Hu, C.-H., Reddy, M. S., Wei, H.-X., Pare, P. W., and Kloepper, J. W. 2003. Bacterial volatiles promote growth in Arabidopsis. Proc. Natl. Acad. Sci. U.S.A. 100:4927-4932.

Ryu, C.-M., Farag, M. A., Hu, C.-H., Reddy, M. S., Kloepper, J. W., and Pare, P. W. 2004. Bacterial volatiles induce systemic resistance in Arabidopsis. Plant Physiol. 134:1017-1026.

Sardans, J., Penuelas, J., and Rivas-Ubach, A. 2011. Ecological metabolomics: Overview of current developments and future challenges. Chemoecology 21:191-225.

Saunders, M., Glenn, A. E., and Kohn, L. M. 2010. Exploring the evolutionary ecology of fungal endophytes in agricultural systems: Using functional traits to reveal mechanisms in community processes. Evol. Appl. 3:525-537.

Schiestl, F. P., Steinebrunner, F., Schulz, C., von Reuss, S., Francke, W., Weymuth, C., and Leuchtmann, A. 2006. Evolution of 'pollinator'attracting signals in fungi. Biol. Lett. 2:401-404.

Schulz, S., and Dickschat, J. S. 2007. Bacterial volatiles: The smell of small organisms. Nat. Prod. Rep. 24:814-842.

Soylu, S., Yigitbas, H., Soylu, E. M., and Kurt, S. 2007. Antifungal effects of essential oils from oregano and fennel on Sclerotinia sclerotiorum. J. Appl. Microbiol. 103:1021-1030.

Splivallo, R., Novero, M., Bertea, C. M., Bossi, S., and Bonfante, P. 2007. Truffle volatiles inhibit growth and induce an oxidative burst in Arabidopsis thaliana. New Phytol. 175:417-424.

Steinebrunner, F., Schiestl, F. P., and Leuchtmann, A. 2008a. Ecological role of volatiles produced by Epichloë: Differences in antifungal toxicity. FEMS (Fed. Eur. Microbiol. Soc.) Microbiol. Ecol. 64:307-316.

Steinebrunner, F., Twele, R., Francke, W., Leuchtmann, A., and Schiestl, F.P. 2008b. Role of odour compounds in the attraction of gamete vectors in endophytic Epichlö̈ fungi. New Phytol. 178:401-411.

Strobel, G. 2006a. Harnessing endophytes for industrial microbiology. Curr. Opin. Microbiol. 9:240-244.

Strobel, G. 2006b. Muscodor albus and its biological promise. J. Ind Microbiol. Biotechnol. 33:514-522.

Strobel, G. A., Dirkse, E., Sears, J., and Markworth, C. 2001. Volatile antimicrobials from Muscodor albus, a novel endophytic fungus. Microbiology 147:2943-2950.

Thacker, J. R. M., and Train, M. R. 2010. Use of volatiles in pest control Pages 151-172 in: The Chemistry and Biology of Volatiles. John Wiley \& Sons, Hoboken, NJ, U.S.A.

Thomma, B. P. H. J., Nurnberger, T., and Joosten, M. H. A. J. 2011. Of PAMPs and effectors: The blurred PTI-ETI dichotomy. Plant Cell 23:415 .
Verhulst, N. O., Mukabana, W. R., Takken, W., and Smallegange, R. C. 2011. Human skin microbiota and their volatiles as odour baits for the malaria mosquito Anopheles gambiae s.s. Entomol. Exp. Appl. 139:170-179.

Vespermann, A., Kai, M., and Piechulla, B. 2007. Rhizobacterial volatiles affect the growth of 18 fungi and Arabidopsis thaliana. Appl. Environ. Microbiol. 73:5639-5641.

Vickers, C. E., Gershenzon, J., Lerdau, M. T., and Loreto, F. 2009. A unified mechanism of action for volatile isoprenoids in plant abiotic stress. Nat. Chem. Biol. 5:283-291.

Wenke, K., Kai, M., and Piechulla, B. 2010. Belowground volatiles facilitate interactions between plant roots and soil organisms. Planta 231:499-506.

Wenke, K., Wanke, D., Kilian, J., Berendzen, K., Harter, K., and Piechulla, B. 2012a. Volatiles of two growth-inhibiting rhizobacteria commonly engage AtWRKY18 function. Plant J. 70:445-459.

Wenke, K., Weise, T., Warnke, R., Valverde, C., Wanke, D., Kai, M., and Piechulla, B. 2012b. Bacterial volatiles mediating information between bacteria and plants. Pages 327-347 in: Biocommunication of Plants. G. Witzany and F. Baluska, eds. Springer-Verlag, Berlin.

Yi, H.-S., Ryu, C.-M., and Heil, M. 2010. Sweet smells prepare plants for future stress: Airborne induction of plant disease immunity. Plant Signal. Behav. 5:528-531.

Zhang, C.-L., Wang, G.-P., Mao, L.-J., Komon-Zelazowska, M., Yuan, Z.-L., Lin, F.-C., Druzhinina, I. S., and Kubicek, C. P. 2010. Muscodor fengyangensis sp. nov. from southeast China: Morphology, physiology and production of volatile compounds. Fungal Biol. 114:797-808

Zhang, H., Kim, M.-S., Krishnamachari, V., Payton, P., Sun, Y., Grimson, M., Farag, M. A., Ryu, C.-M., Allen, R., Melo, I. S., and Pare, P. W. 2007. Rhizobacterial volatile emissions regulate auxin homeostasis and cell expansion in Arabidopsis. Planta 226:839-851.

Zhang, H., Kim, M.-S., Sun, Y., Dowd, S. E., Shi, H. Z., and Pare, P. W. 2008a. Soil bacteria confer plant salt tolerance by tissue-specific regulation of the sodium transporter HKT1. Mol. Plant-Microbe Interact. 21:737-744.

Zhang, H., Xie, X., Kim, M.-S., Kornyeyev, D. A., Holaday, S., and Pare, P. W. 2008b. Soil bacteria augment Arabidopsis photosynthesis by decreasing glucose sensing and abscisic acid levels in planta. Plant $\mathbf{J}$. 56:264-273.

Zhang, P., and Chen, K. 2009. Age-dependent variations of volatile emissions and inhibitory activity toward Botrytis cinerea and Fusarium oxysporum in tomato leaves treated with chitosan oligosaccharide. J. Plant Biol. 52:332-339.

Zhang, Z., and Li, G. 2010. A review of advances and new developments in the analysis of biological volatile organic compounds. Microchem. J. 95:127-139.

Zou, C.-S., Mo, M.-H., Gu, Y.-Q., Zhou, J.-P., and Zhang, K.-Q. 2007. Possible contributions of volatile-producing bacteria to soil fungistasis. Soil Biol. Biochem. 39:2371-2379. 